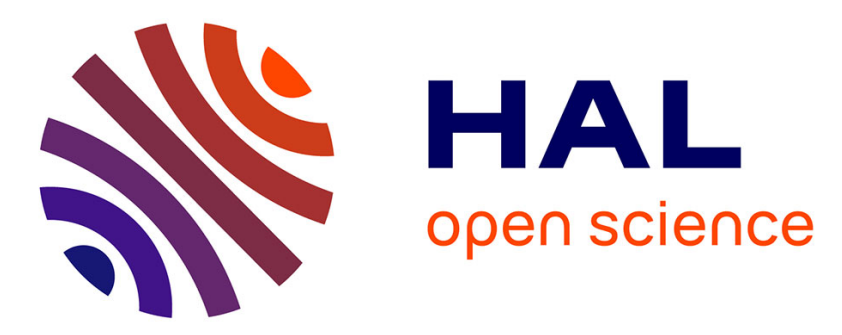

\title{
THE EFFECT OF NOZZLE ELECTRIFICATION ON SPRAY FORMATION FROM AN AIRBLAST ATOMIZER
}

Theodore J Heindel, Julie K Bothell, Thomas J Burtnett, Danyu Li, Timothy R. Morgan, Alberto Aliseda, Nathanaël Machicoane, Katarzyna E Matusik, Alan L Kastengren

\section{To cite this version:}

Theodore J Heindel, Julie K Bothell, Thomas J Burtnett, Danyu Li, Timothy R. Morgan, et al.. THE EFFECT OF NOZZLE ELECTRIFICATION ON SPRAY FORMATION FROM AN AIRBLAST ATOMIZER. 4th Thermal and Fluids Engineering Conference, Apr 2019, Las Vegas, United States. pp.14 - 17, 10.1615/TFEC2019.spr.028854 . hal-02516285

\section{HAL Id: hal-02516285 \\ https://hal.science/hal-02516285}

Submitted on 23 Mar 2020

HAL is a multi-disciplinary open access archive for the deposit and dissemination of scientific research documents, whether they are published or not. The documents may come from teaching and research institutions in France or abroad, or from public or private research centers.
L'archive ouverte pluridisciplinaire HAL, est destinée au dépôt et à la diffusion de documents scientifiques de niveau recherche, publiés ou non, émanant des établissements d'enseignement et de recherche français ou étrangers, des laboratoires publics ou privés. 


\title{
THE EFFECT OF NOZZLE ELECTRIFICATION ON SPRAY FORMATION FROM AN AIRBLAST ATOMIZER
}

\author{
Theodore J. Heindel ${ }^{1 *}$, Julie K. Bothell ${ }^{1}$, Thomas J. Burtnett ${ }^{1}$, Danyu Li $^{1}$, Timothy B. Morgan ${ }^{1}$, \\ Alberto Aliseda $^{2}$, Nathanaël Machicoane ${ }^{2}$, Katarzyna E. Matusik ${ }^{3}$, and Alan L. Kastengren ${ }^{3}$ \\ ${ }^{1}$ Iowa State University, Ames, IA 50011-2161, USA \\ ${ }^{2}$ University of Washington, Seattle, WA 98195-2600, USA \\ ${ }^{3}$ Argonne National Laboratory, Argonne, IL 60439, USA
}

\begin{abstract}
Liquid sprays play a key role in many engineering processes (e.g., food processing, coating and painting, 3D printing, fire suppression, combustion systems, etc.). The conditions at the nozzle exit have a large influence on the downstream spray characteristics. However, characterizing the spray in this region is extremely challenging because under most operating conditions the spray is optically dense. High intensity white beam X-ray imaging and focused beam radiography, like that available at the Advanced Photon Source (APS) at Argonne National Laboratory, can be used to produce time-resolved visualizations and measurements of the spray near-field region. In this study, high spatially- and temporally-resolved X-ray data are acquired of a canonical airblast atomizer consisting of coaxial water and air jets. The liquid is charged by flowing it through a metallic duct electrified to $-5 \mathrm{kV}$ with the motivation to enhance the atomization process. High-speed X-ray images and measured equivalent path lengths are compared with and without the electric potential and with and without gas swirl. It is shown that the electrification of the liquid needle has a negligible effect in the spray near-field for the conditions used in this study.
\end{abstract}

KEY WORDS: Airblast atomizer, Electrified nozzle, Equivalent path length, Sprays, Synchrotron X-rays, X-ray imaging

\section{INTRODUCTION}

The ability to control spray formation and dispersion is extremely important to many spray applications, including coating and painting, fire suppression, agricultural applications, and liquid fuel combustion. Spray regions are generally identified as near-field, mid-field, and far-field, with the demarcation between regions being nebulous. The near-field region is closest to the nozzle exit and can influence mid- and far-field characteristics; however, near-field measurements are extremely challenging because the spray in this region is typically optically dense, rendering optical/laser diagnostics largely ineffective. This study uses synchrotron radiation, available at the Advanced Photon Source (APS) at Argonne National Laboratory, to obtain high spatial and temporal data of the near-field region of an airblast atomizer. The inner liquid flow is energized with $-5 \mathrm{kV}$ of DC potential to determine the effect of adding electric charge to the liquid on spray dispersion. Data are presented for a single liquid Reynolds number of $\mathrm{Re}_{1}=1000$ and gas Reynolds number of $\mathrm{Re}_{\mathrm{g}}=16,700$, corresponding to a gas-liquid momentum ratio of 5 . Gas swirl and no swirl are also investigated while the gas flow rate is held fixed.

\section{EXPERIMENTAL PROCEDURES}

The airblast atomizer used in this study has been described in detail elsewhere [1]. Fig. 1 shows a close-up of the airblast atomizer, identifying the aluminium liquid needle that is energized to $-5 \mathrm{kV}$ and the copper grounding ring at the nozzle exit. The system is designed to charge the liquid as it is issued from the liquid 


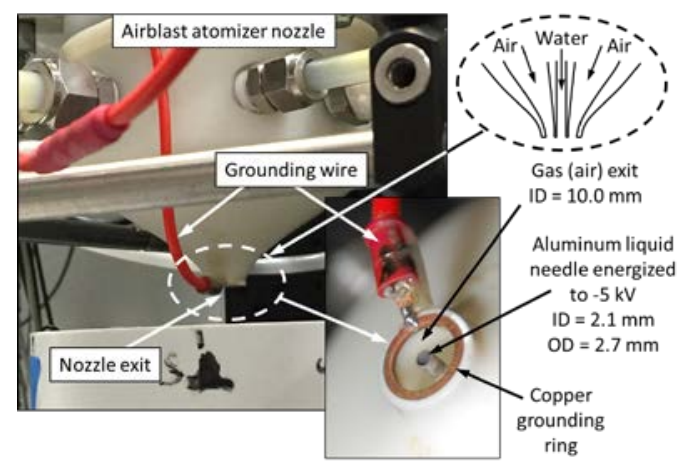

Fig. 1 Picture of the airblast atomizer set-up for electrified operation.

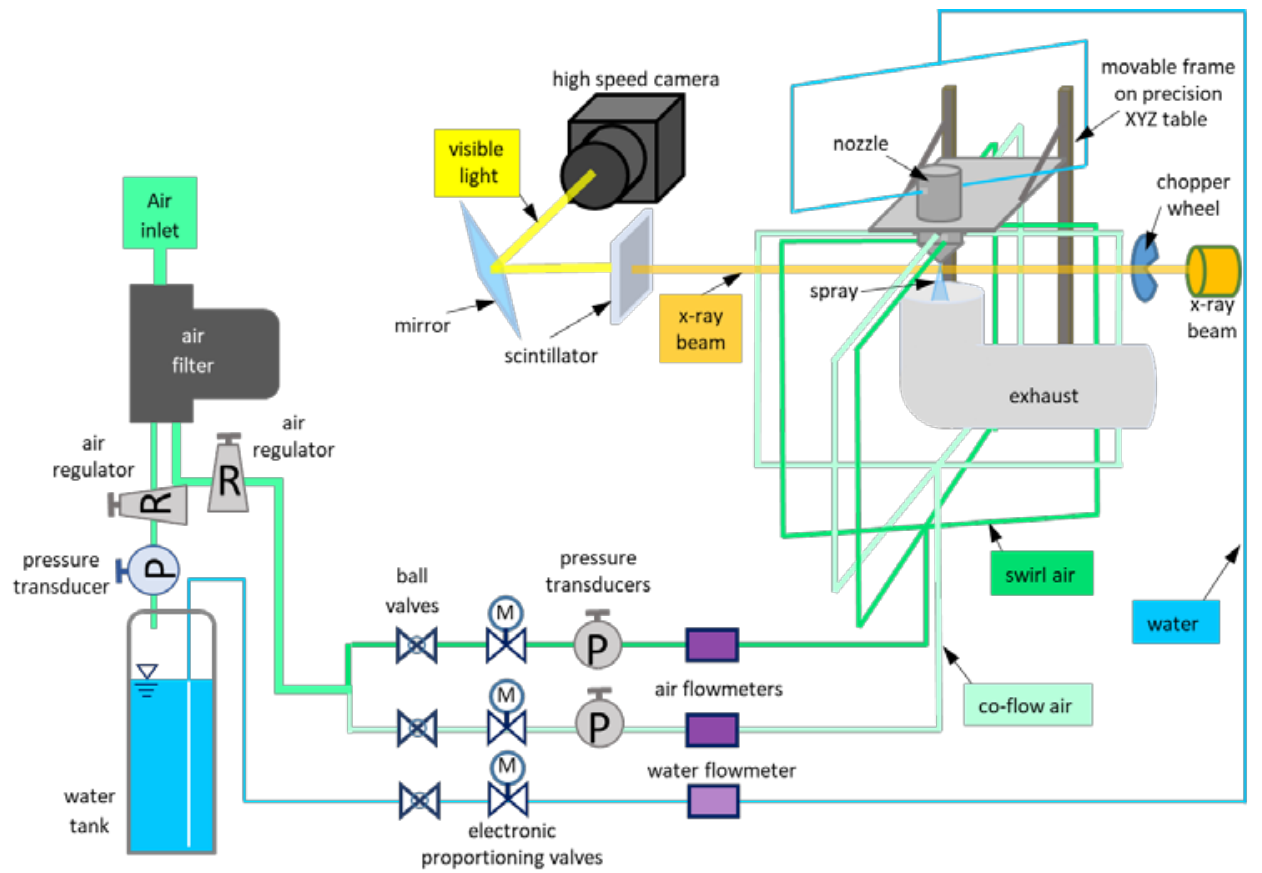

Fig. 2 Schematic of the airblast atomizer flow loop and white beam imaging set-up.

needle and the surrounding gas flow provides the momentum to atomize the liquid. The outer portion of the gas exit is grounded to intensify the electric field at the nozzle exit plane, hence increasing the liquid charging.

The nozzle was mounted on a traversing stand that allowed for its placement at a desired location within the X-ray beam at the Advanced Photon Source. A schematic of the entire experimental set-up is shown in Fig. 2. White beam and focused beam imaging were completed in this study; details of these experimental techniques can be found elsewhere [2].

The nozzle is designed to allow air entry that is perpendicular to the liquid needle axis or tangential to the liquid needle axis. A swirl ratio is defined as the ratio of tangential air inlet flow rate to perpendicular air inlet flow rate, while the total air flow rate is constant (fixed $\mathrm{Re}_{\mathrm{g}}$ ). In this study, conditions for $\mathrm{SR}=0$ and $\mathrm{SR}=1$ are presented while the liquid flow rate was fixed at $\operatorname{Re}_{\mathrm{l}}=1000$ and the gas flow rate was fixed at $\operatorname{Re}_{\mathrm{g}}=16,700$, and the liquid needle was set with $\mathrm{V}=0 \mathrm{kV}$ and $\mathrm{V}=-5 \mathrm{kV}$.

\section{RESULTS}

Fig. 3 shows two white beam X-ray images taken at the nozzle exit with $\mathrm{SR}=1$, without and with electrification. The nozzle exit plane is identified and the liquid needle walls are schematically shown. The different gray scales 


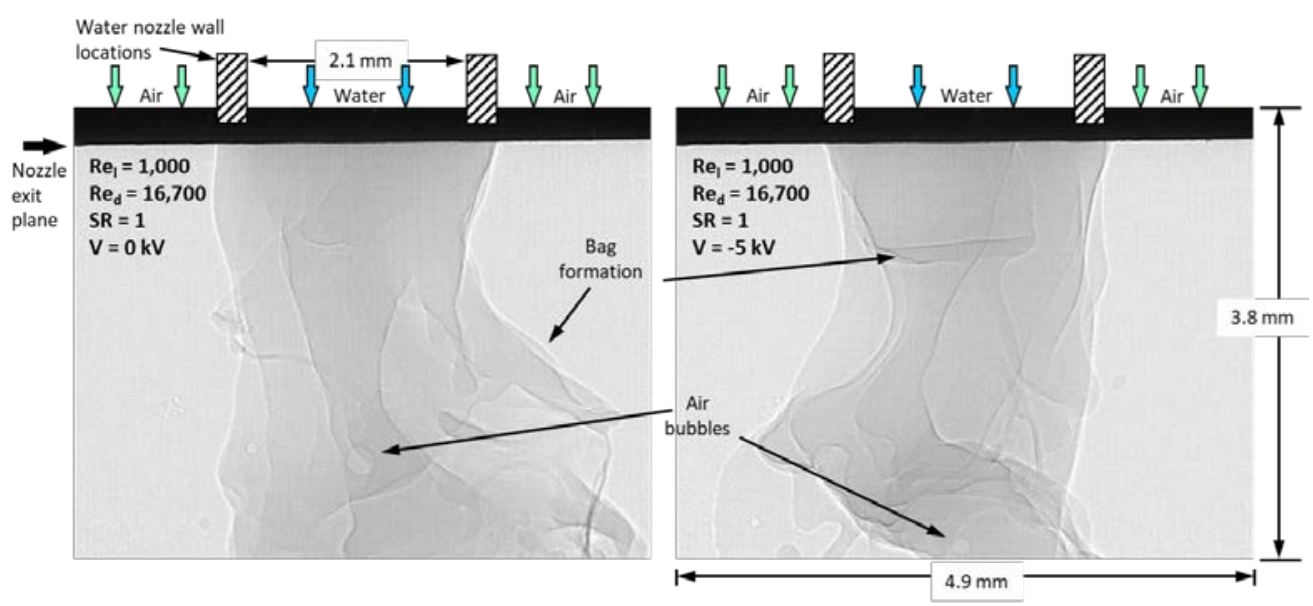

Fig. 3 White beam X-ray images of an airblast atomizer with V $=0 \mathrm{kV}$ (left) and V $=-5 \mathrm{kV}$ (right).
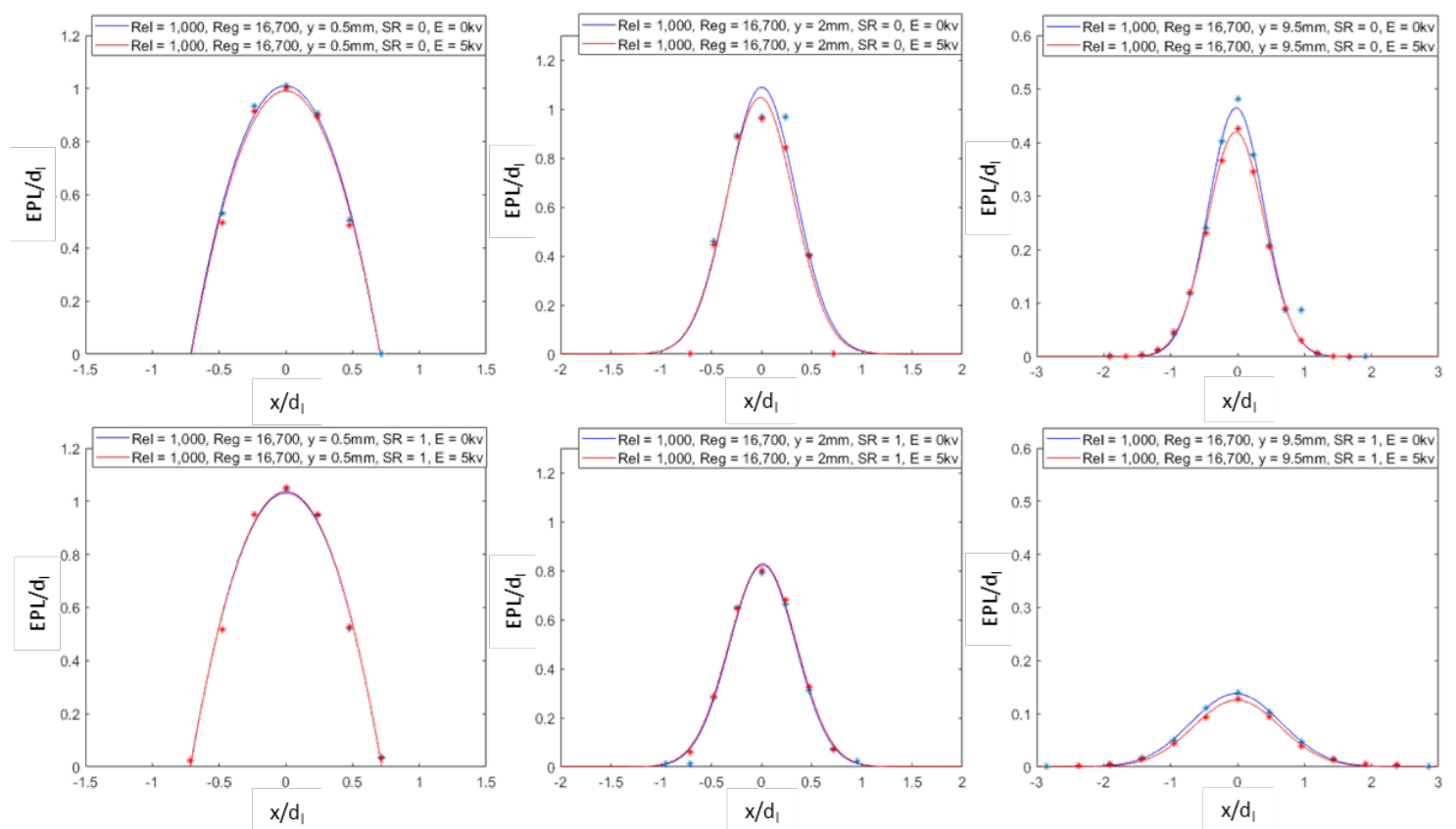

Fig. 4 Equivalent path lengths (EPL) obtained from focused beam X-ray measurements at different axial locations with SR $=0$ (top, $\mathrm{y}=0.5 \mathrm{~mm}, 2 \mathrm{~mm}$, and $9.5 \mathrm{~mm}$ ) and SR $=1$ (bottom, $\mathrm{y}=0.5 \mathrm{~mm}, 2 \mathrm{~mm}$, and $9.5 \mathrm{~mm}$ ). Each plot includes $\mathrm{V}=0$ and $\mathrm{V}=-5 \mathrm{kV}$ conditions.

in the water region outside the nozzle exit plane indicate different thicknesses of water, where darker regions are associated with more water. Under these flow conditions, the water wets the liquid needle tip making the exit diameter larger than the needle inside diameter. The water can even wick up the outside needle region [3]. Instabilities periodically form along the gas-liquid interface in which it appears that gas tries to penetrate the liquid, forming a bag (identified in the images). The bag grows and deforms the liquid jet, leading to ligament formation and eventually droplets (which appear much further downstream). One unique ability of white beam X-ray imaging is that air bubbles within the liquid region are visible, which is not possible using optical visualization methods. Qualitative analysis of the visual observations between the energized and de-energized system indicate only small differences between the two flow conditions where bag formations is observed further upstream when the liquid nozzle is charged.

Fig. 4 shows the equivalent path lengths (EPL) obtained using focused beam X-ray measurements, nondimensionalized by the liquid needle ID $(2.1 \mathrm{~mm})$. EPL measurements show the total liquid path length through the spray at the given dimensionless x-coordinate (i.e., line-of-sight measures). It has been shown using 
this technique that the liquid region EPL in the spray region follows a Gaussian distribution $[4,5]$. As shown in Fig. 4, when $y=0.5 \mathrm{~mm}$ from the nozzle exit, the liquid region is still continuous (verified in the white beam images in Fig. 3) and are better represented by a parabolic profile (shown). As the liquid region begins to break up, the EPL profiles match the Gaussian distribution as displayed by the continuous lines when $\mathrm{y}=2.0 \mathrm{~mm}$ and $y=9.5 \mathrm{~mm}$. As shown in Fig. 4, the effect of energizing the liquid needle has only a small effect on the EPL profiles where the EPL is decreased slightly when $-5 \mathrm{kV}$ of energy is applied, and this is apparent only at an axial distance of $\mathrm{y}=9.5 \mathrm{~mm}$.

A more significant effect on the EPL profiles is the effect of gas swirl, where swirl causes the profile to widen and flatten [6], and this effect becomes more severe as the axial distance from the nozzle exit increases.

\section{CONCLUSIONS}

White beam X-ray imaging and focused beam radiography were used to assess the effect of nozzle electrification on the near-field spray characteristics from an airblast atomizer. For the fixed liquid and gas Reynolds numbers of this study, the effect of energizing the liquid needle with $-5 \mathrm{kV}$ potential was only observed at an axial location of $y=9.5 \mathrm{~mm}$ from the nozzle exit, and then it only reduced the equivalent path length by a small amount. However, effects on instabilities and breakup mechanisms are expected in the mid-field and investigations in this region are currently underway using different diagnostic techniques. Furthermore, it was shown that gas swirl had a more significant effect on equivalent path length in the nearfield.

\section{ACKNOWLEDGMENT}

This work was sponsored by the Office of Naval Research (ONR) as part of the Multidisciplinary University Research Initiatives (MURI) Program, under grant number N00014-16-1-2617. The views and conclusions contained herein are those of the authors only and should not be interpreted as representing those of ONR, the U.S. Navy, or the U.S. Government. This work was performed at the 7-BM beamline of the Advanced Photon Source, a U.S. Department of Energy (DOE) Office of Science User Facility operated for the DOE Office of Science by Argonne National Laboratory under Contract No. DE-AC02-06CH11357.

\section{REFERENCES}

[1] Machicoane, N. and Aliseda, A., "Experimental Characterization of a Canonical Coaxial Gas-Liquid Atomizer," ILASS Americas 2017: 29th Annual Conference on Liquid Atomization and Spray Systems, Atlanta, GA, May 15-18, (2017).

[2] Heindel, T.J., "Recent Advances in Spray Diagnostics using X-rays," ILASS - Americas 2017: 29th Annual Conference on Liquid Atomization and Spray Systems, Atlanta, GA, May 15-18, (2017).

[3] Li, D., Bothell, J.K., Morgan, T.B., Heindel, T.J., Aliseda, A., Machicoane, N., and Kastengren, A.L., "High-speed X-ray Imaging of an Airblast Atomizer at the Nozzle Exit," APS-DFD Gallery of Fluid Motion

https://doi.org/10.1103/APS.DFD.2017.GFM.V0026, 2017 APS-DFD Meeting, Denver, CO, November 19 - 21, (2017).

[4] Powell, C.F., Yue, Y., Poola, R., and Wang, J., "Time-Resolved Measurements of Supersonic Fuel Sprays using Synchrotron X-rays," Journal of Synchrotron Radiation, 7(6): pp. 356-360, (2000).

[5] Yue, Y., Powell, C.F., Poola, R., Wang, J., and Schaller, J.K., "Quantitative Measurements of Diesel Fuel Spray Characteristics in the Near-Nozzle Region using X-ray Absorption," Atomization and Sprays, 11(4): pp. 471-490, (2001).

[6] Bothell, J.K., Li, D., Morgan, T.B., Heindel, T.J., Aliseda, A., Machicoane, N., and Kastengren, A., "Characterizing the NearField Region of a Spray using White Beam and Focused Beam X-ray Measurements," ICLASS 2018, 14th Triennial International Conference on Liquid Atomization and Spray Systems, Chicago, IL, July 22-26, (2018). 